\title{
Desipramine Modulation of $\alpha-, \gamma$-Synuclein, and the Norepinephrine Transporter in an Animal Model of Depression
}

\author{
Alexis M Jeannotte ${ }^{1,2}$, John G McCarthy', Eva E Redei ${ }^{3}$ and Anita Sidhu*,1,2 \\ 'Department of Biochemistry and Molecular and Cell Biology, Georgetown University Medical Center, Georgetown University, Washington, DC, \\ USA; ${ }^{2}$ Interdisciplinary Program in Neuroscience, Georgetown University Medical Center, Georgetown University, Washington, DC, USA; \\ ${ }^{3}$ Department of Psychiatry and Behavioral Sciences, Northwestern University, Chicago, IL, USA
}

\begin{abstract}
The mechanisms underlying depression remain elusive. We previously determined that $\alpha$-synuclein ( $\alpha$-Syn) modulates the activity and trafficking of the norepinephrine transporter (NET) in a manner that is dependent on its interactions with microtubules (MTs). Here we sought to determine if $\alpha$-Syn, or the other synuclein family members, $\beta$-synuclein ( $\beta$-Syn) and $\gamma$-synuclein $(\gamma$-Syn), modulate NET activity in an animal model of depression, the Wistar-Kyoto (WKY) rat. The NET-selective antidepressant desipramine (DMI) was chronically administered for 14 days to WKY rats and the strain from which it was outbred that does not show depressive-like behavior, the Wistar rat. This drug regimen induced significant behavioral improvements in the WKY, but not the Wistar rat, in the forced swim test. In WKY rats there was an overexpression of $\gamma$-Syn which was reduced following DMI treatment. In parallel, DMI caused an increase in both $\alpha$-Syn and NET in the frontal cortex. Frontal cortex synaptosomes from WKY rats were not sensitive to nocodazole, a compound that promotes MT destabilization. However, in WKYs treated with DMI, nocodazole induced an increase in $\left[{ }^{3} \mathrm{H}\right]-\mathrm{NE}$ uptake. This trend was reversed in Wistars. Underlying these DMI-induced changes were alterations in the protein interactions between the synucleins and NET with the tubulins. These results are the first to implicate $\alpha$-Syn or $\gamma$-Syn in the pathophysiology of depression and suggest that targeting synucleins may provide a new therapeutic option for depression.

Neuropsychopharmacology (2009) 34, 987-998; doi:I0.1038/npp.2008.146; published online 17 September 2008
\end{abstract}

Keywords: $\alpha$-synuclein; $\gamma$-synuclein; desipramine; microtubule; Parkinson's disease; depression

\section{INTRODUCTION}

The cellular and molecular pathology underlying the development and progression of depression remains unclear (Frazer, 1997). An important finding that has aided the understanding of the disease pathology was that of Klimek et al (1997) who found a reduction in norepinephrine transporter (NET) expression in the locus coeruleus of post-mortem tissue from patients with depression (Klimek et al, 1997). Chronic treatment with the NETselective antidepressant, desipramine (DMI), not only decreased NET activity (Benmansour et al, 2004), but also downregulated the binding and expression of the transporter (Bauer and Tejani-Butt, 1992; Hebert et al, 2001; Zhu et al, 2002). Previously, we determined that the trafficking, cellular localization, and activity of NET is regulated by

\footnotetext{
*Correspondence: Dr A Sidhu, Laboratory of Molecular Neurochemistry, Research Building, Room W222, 3970 Reservoir Road, NW, Washington, DC 20007, USA, Tel: + 202687 0273, Fax: + 202687 0279, E-mail: sidhua@georgetown.edu

Received 19 May 2008; revised 12 August 2008; accepted 13 August 2008
}

$\alpha$-synuclein ( $\alpha$-Syn) in a manner that is dependent on the expression levels of $\alpha$-Syn and an intact microtubule (MT) network (Jeannotte and Sidhu, 2007; Wersinger et al, 2006a). Specifically, $\alpha$-Syn aids in trafficking NET away from the cell surface by tethering the transporter to MTs, reducing its expression at the cell surface, whereas simultaneously decreasing its reuptake activity. The ability of $\alpha$-Syn to regulate the trafficking and function of NET and the serotonin transporter (SERT; Wersinger et al, 2006b) suggests a potential role for $\alpha$-Syn in the genesis and maintenance of depression.

$\alpha$-Syn, a presynaptic MT-associated protein whose precise function remains unknown, has been extensively studied in Parkinson's disease (PD) pathology (Clayton and George, 1999; Goedert, 2001; Lee and Trojanowski, 2006; Sidhu et al, 2004). In $\alpha$-Syn knockout mice there is an enhanced refilling rate of synaptic vesicles with norepinephrine (NE) following prolonged stimulation, suggesting an intimate link between $\alpha$-Syn physiology and noradrenergic homeostasis (Yavich et al, 2006). This finding also illustrates $\alpha$-Syn's role in regulating the synaptic tone and thus may be involved in other pathologies, such as depression, that involve synaptic 
dysregulation of monoamine neurotransmitters. The other members of the synuclein family are $\beta$ - and $\gamma$-synuclein $(\beta$ Syn, $\gamma$-Syn), whose function remains elusive (Clayton and George, 1998). $\gamma$-Syn is expressed in the central nervous system (Brenz Verca et al, 2003; Surguchov et al, 1999, 2001) and periphery. $\gamma$-Syn is upregulated in some breast and prostate cancers, and cells expressing this protein have been found to be resistant to specific chemotherapeutic agents that disrupt the cytoskeleton (Gupta et al, 2003a, b; Ji et al, 1997; Pan et al, 2002; Wu et al, 2003). In addition, $\gamma$ Syn has chaperone and trafficking capabilities (Liu et al, 2007) and associates with the mitotic spindle, a cellular formation present during MT reorganization (Gupta et al, 2003b; Inaba et al, 2005; Surguchov et al, 2001). In contrast, $\beta$-Syn plays many roles within the cell, yet many of its identified activities are thought to antagonize those of $\alpha$-Syn (Fan et al, 2006; Hashimoto et al, 2001; Lee et al, 2004; Uversky et al, 2002).

Approximately $40 \%$ of PD patients are diagnosed with depression before the clinical diagnosis of their motor symptoms (Allain et al, 2000; Taylor et al, 1986). The high incidence of comorbidity and our previous findings that $\alpha$ Syn regulates NET and SERT, together suggest that depression and PD may be related by an overlapping cellular pathway involving $\alpha$-Syn. Specifically, we hypothesized that the reduced bioavailability of $\alpha$-Syn is a contributing factor in both depression and $\mathrm{PD}$, and the current studies were undertaken to test this hypothesis. These proteins and their interactions were analyzed after chronic treatment with DMI in an established rodent model of depression, the Wistar-Kyoto (WKY) rat, and the Wistar rat, from which the WKY was outbred, but which does not display depressive-like behavior.

\section{MATERIALS AND METHODS}

\section{Materials and Antibodies}

Monoclonal anti-NET was purchased from MAb Technologies (Stone Mountain, GA). Polyclonal anti-NET and anti$\alpha$-Syn were obtained from Chemicon (Temecula, CA). Monoclonal anti- $\alpha$-Syn was purchased from BD Transduction Labs (San Diego, CA). Anti- $\gamma$-Syn was purchased from AbCam (Cambridge, MA). Anti- $\alpha$-Syn, C-20 and N-19, anti$\beta$-Syn, anti- $\beta$-actin, and secondary antibodies were purchased from Santa Cruz (Santa Cruz, CA). DMI, NE, and nocodazole were purchased from Sigma (St Louis, MO). $\left[{ }^{3} \mathrm{H}\right]$-nisoxetine ([$\left.{ }^{3} \mathrm{H}\right]-\mathrm{NSX}$; NET1084; $\left.80 \mathrm{Ci} / \mathrm{mmol}\right)$, was obtained from New England Nuclear (PerkinElmer, Wellesley, MA).

\section{Animals and Tissue}

The Georgetown University Animal Care and Use Committee and the Northwestern University Animal Care and Use Committee approved all animal procedures. Male Wis and WKY rats were obtained from Harlan (Indianapolis, IN). Animals were housed 2-3 per cage, fed ad libitum, and kept in a $24 \mathrm{~h} \mathrm{light/dark}$ cycle. All adult animals were killed at 16-20 weeks of age and treated starting at 16 weeks. Animals were either used for behavioral testing or killed $24 \mathrm{~h}$ following the last treatment. Animals used for acute studies of antidepressant treatment were killed $24 \mathrm{~h}$ after the first treatment. WKY and Wis animals were given once daily subcutaneous injections of either DMI $(10 \mathrm{mg} / \mathrm{kg}$ per day) or saline, then used for behavioral analysis or killed to collect and use the brain tissue. Following decapitation, the brain tissue was dissected on ice and either snap-frozen at $-80^{\circ} \mathrm{C}$ for later biochemical analysis or used immediately for the preparation of synaptosomes.

\section{Behavioral Analysis}

The forced swim test (FST) was adapted from Porsolt $e$ t al (1978). The test was carried out as originally designed but after a 13-day daily administration of DMI. Briefly, in the pretest, rats were placed in the water tank for $15 \mathrm{~min}$. The swim test was repeated $24 \mathrm{~h}$ later for $5 \mathrm{~min}, 1 \mathrm{~h}$ after the animals received their last DMI or vehicle (saline) injections. The number of 5-s bins spent immobile and the number of climbings were recorded as described by Detke et al (1995).

\section{Cell Culture and Transfections}

Transformed mouse fibroblast cell line $\mathrm{L}^{-}$cells were grown in Dulbecco's modified Eagle's medium (DMEM; Cellgro) supplemented with $10 \%$ fetal bovine serum (Sigma), $1 \%$ glutamate (Sigma), and $1 \%$ antibiotic/antimycotic (Sigma) in a $37^{\circ} \mathrm{C} / 5 \% \mathrm{CO}_{2}$ incubator. NET DNA was a gift from Dr Randy Blakely at Vanderbilt University, $\alpha$-Syn from Dr Ted Dawson at Johns Hopkins University, and $\beta$-Syn and $\gamma$-Syn from Dr Vladimir Buchmann at Cardiff University. All constructs were subcloned into a pcDNA3.1 vector (Invitrogen), transiently transfected using Fugene (Roche) according to the manufacturer's instructions, and plated as described previously (Jeannotte and Sidhu, 2007).

\section{Synaptosome Preparation}

Synaptosomes were prepared from freshly killed animals as described previously (Jeannotte and Sidhu, 2007). Briefly, the tissue was suspended in $10 \% \mathrm{w} / \mathrm{v}$ synaptosome homogenizing buffer, homogenized on ice, and centrifuged at $500 \mathrm{~g}$ for $10 \mathrm{~min}$ at $4^{\circ} \mathrm{C}$. The supernatant was spun at $25000 \mathrm{~g}$ for $15 \mathrm{~min}$ at $4^{\circ} \mathrm{C}$. The protein concentration was determined and diluted to $100 \mu \mathrm{g} / \mathrm{ml}$ in modified KrebsHepes buffer and used for uptake and kinetic experiments.

\section{Treatments}

All treatments were dissolved and stored in DMSO in a concentrated form. After addition of the treatments in uptake buffer or serum-free media, samples were incubated at $37^{\circ} \mathrm{C}$ for $1 \mathrm{~h}$, and then used for assays. Cell viability following treatment was determined by Trypan blue exclusion test and MTT cell viability assay. All the doses presented here were nontoxic.

\section{$\left[{ }^{3} \mathrm{H}\right]-\mathrm{NE}$ Uptake Assays and Treatments}

Uptake assays were performed on intact and adherent transiently transfected cells or freshly prepared synapto- 
somes as described previously (Jeannotte and Sidhu, 2007). Briefly, uptake into cells was performed using room temperature uptake buffer (Krebs-Ringer-Hepes) and a final concentration of $20 \mathrm{nM}\left[{ }^{3} \mathrm{H}\right]-\mathrm{NE}$. Cells were homogenized in $0.1 \mathrm{~N} \mathrm{NaOH}$, an aliquot taken for protein assay, and the rest read using a Beckman Liquid Scintillation counter. The synaptosome assay mixture was incubated at $37^{\circ} \mathrm{C}$ with nocodazole for $1 \mathrm{~h}$, followed by the addition of $\left[{ }^{3} \mathrm{H}\right]-\mathrm{NE}$ at a final concentration of $20 \mathrm{nM}$. Uptake proceeded for $5 \mathrm{~min}$ and was terminated with cold $0.32 \mathrm{M}$ sucrose buffer. Filtration was performed on a 24-sample Brandel Cell Harvester and samples were collected on GF/C Whatman filters that were presoaked in $0.1 \%$ polyethylenamine. Filters were collected, scintillation cocktail added, and read as for uptake assays as above. Nonspecific uptake was determined in $10 \mu \mathrm{M}$ DMI or $1 \mu \mathrm{M}$ DMI, other transport blockers, at $4{ }^{\circ} \mathrm{C}$, and in uptake buffer without $\mathrm{Na}+$ or $\mathrm{Cl}-$ ions for cells or synaptosomes, respectively (Jeannotte and Sidhu, 2007).

\section{Immunoblotting}

Proteins from brain tissue were isolated in homogenization buffer $(20 \mathrm{mM}$ Tris $\mathrm{pH} 7.5,5 \mathrm{mM} \mathrm{KCl}, 200 \mu \mathrm{M}$ sodium orthovanadate, protease inhibitor cocktail (Roche)), sonicated, and spun ( $1850 \mathrm{~g}$ for $10 \mathrm{~min}$ at $4^{\circ} \mathrm{C}$ ). The protein concentration of the supernatant was determined, diluted in dilution buffer $(20 \mathrm{mM}$ Tris $\mathrm{pH} 7.4,200 \mu \mathrm{M}$ sodium orthovanadate, $1 \mathrm{mM}$ EDTA, $1 \mathrm{mM}$ EGTA, one tablet per $10 \mathrm{ml}$ protease inhibitors) and laemmli buffer (Bio-Rad) with $10 \% \beta$-mercaptoethanol, heated at $65^{\circ} \mathrm{C}$ for $30 \mathrm{~min}$ or heated in boiling water for $5 \mathrm{~min}$ to resolve $\alpha$-Syn protein. Samples were electrophoresed either on SDS-polyacrylamide gels or on Nu-PAGE ${ }^{\mathrm{TM}} 4-12 \%$ Bis-Tris polyacrylamide gradient gels as described before (Moussa et al, 2004) and transferred onto PVDF membranes (Millipore). Blots were blocked, probed, and imaged as described previously (Wersinger et al, 2006a) using anti-NET mAb (monoclonal antibody, 1:1000; MAb Technologies), anti- $\alpha$-Syn mAb (1:500; BD Transduction Labs), anti- $\beta$-Syn (1:1000; Santa Cruz), anti- $\gamma$-Syn pAb (polyclonal antibody, 1:2000; AbCam), anti- $\alpha$ - or $\beta$-tubulin mAb (1:1000; Santa Cruz), anti- $\beta$-actin mAb (1:500; Santa Cruz), HRP-conjugated secondary antibodies (1:5000; Santa Cruz), and enhanced chemiluminescence (PerkinElmer). Images were scanned and quantified using ScionImage.

\section{Subcellular Fractionation}

For WKY and Wis brain tissue, samples were prepared similarly to those described for Sprague-Dawley (SD) rats, but after centrifugation an aliquot of the supernatant was removed and denoted as the total homogenate. Then extraction buffer ( $1 \%$ Triton $-\mathrm{X}-100,10 \mathrm{mM}$ imidazole, $100 \mathrm{mM} \mathrm{NaCl}, 1 \mathrm{mM} \mathrm{MgCl}_{2}, 5 \mathrm{mM}$ EDTA, $0.5 \mathrm{mM} \mathrm{NaF}$, $1 \mathrm{mM}$ sodium vanadate, $250 \mathrm{mM}$ Sucrose, and 1 protease inhibitor tablet) was added to the remaining supernatant in a $1: 1 \mathrm{v} / \mathrm{v}$ ratio and incubated on ice for $30 \mathrm{~min}$. This fraction was centrifuged $\left(25000 \mathrm{~g} ; 15 \mathrm{~min} ; 4^{\circ} \mathrm{C}\right)$ to yield the plasma membrane (pellet) and cytosolic (supernatant) fractions.

\section{Coimmunoprecipitations}

After homogenization of the brain lysates, proteins were solubilized in a modified RIPA buffer $(\sim 1 \mathrm{mg} / \mathrm{ml}$ protein; $50 \mathrm{mM}$ Tris $\mathrm{pH} 7.5,300 \mathrm{mM} \mathrm{NaCl}, 0.5 \%$ Triton $\mathrm{X}-100,0.5 \%$ deoxycholate sodium salt, $0.5 \%$ Nonidet P-40, $1 \mathrm{mM}$ DTT, $200 \mu \mathrm{M}$ sodium orthovanadate, $1 \mathrm{mM}$ EDTA, $1 \mathrm{mM}$ EGTA, one tablet per $10 \mathrm{ml}$ protease inhibitors (Roche)) shaking at $4^{\circ} \mathrm{C}$ for $45 \mathrm{~min}$. After centrifugation $\left(18500 \mathrm{~g} ; 4^{\circ} \mathrm{C} ; 20 \mathrm{~min}\right)$, the supernatant was diluted to $300-600 \mu \mathrm{g} / \mathrm{ml}$ protein with dilution buffer, as described for immunoblotting. Solubilized lysates $(600-900 \mu \mathrm{l}$ per assay; $300-600 \mu \mathrm{g} / \mathrm{ml}$ protein) were precleared for 30 min with $40 \mu \mathrm{l}$ of protein A/G PLUSAgarose (Santa Cruz), then pelleted. Subsequently, either anti-NET pAb (1:100; Chemicon), anti- $\alpha$-Syn pAb (1:100; Santa Cruz), anti- $\gamma$-Syn pAb (1:50; AbCam), anti- $\alpha$ - or $\beta$ tubulins pAb (1:100; Santa Cruz), anti- $\beta$-actin pAb (1:100; Santa Cruz) antibodies, or nonimmune sera $(2-3 \mu \mathrm{g}$ protein) are added for $8 \mathrm{~h}$ with gentle shaking at $4{ }^{\circ} \mathrm{C}$. After precipitation with protein $A / G$ sepharose beads for $90 \mathrm{~min}$, immunopellets are washed 3-5 times with dilution buffer, dissociated in Laemmli buffer for $2 \mathrm{~h}$ at room temperature or by gentle heating for $30 \mathrm{~min}$ at $65^{\circ} \mathrm{C}$, and samples are characterized by immunoblot analysis.

\section{Data Analysis}

All data are represented as the average \pm standard error of the mean. A two-way ANOVA followed by post hoc test, when appropriate was performed to analyze the behavioral measures. A Student's $t$-test was performed to compare western analysis values between WKY and Wistars or saline and DMI-treated animals. Within strain comparisons were made, except in the innate responses in the FST. All uptake and kinetic measurements were performed in triplicate. For comparison of both in vitro and synaptosomal uptake values, as well as expression of other monoamine transporters, a two-way ANOVA was used. Uptake performed using synaptosomes from acutely treated animals was performed using a one-way ANOVA to determine within strain differences at different nocodazole doses. Post hoc analysis was performed using the Bonferroni method with a threshold set at $p<0.05$. Kinetic parameters of $\left[{ }^{3} \mathrm{H}\right]-\mathrm{NSX}$ binding were calculated using nonlinear regression and the Scatchard linear regression analysis program on GraphPad Prism 4.0 (GraphPad Software, San Diego, CA).

\section{RESULTS}

\section{Chronic DMI Treatment Improves Depressive Behavior in WKY Rats}

Depressive behavior in adult WKY and Wis males ( $n=7$ per group) was tested by the FST and responses were quantified by scoring the number of 5-s bins spent either immobile or climbing in the test. The results indicated that WKYs injected with vehicle (saline) spent significantly more time immobile and less time climbing, compared to the Wis rats (Table $1 ; p<0.01$ ). Chronic treatment with DMI (14 days, $10 \mathrm{mg} / \mathrm{kg}$ body weight) significantly reduced immobility in WKYs and increased their climbing behavior, in contrast to the lack of DMI effect on Wis rats. 
Table I Depressive-Like Behavior is Reduced in WKY Rats Chronically Treated with DMI

\begin{tabular}{lcc}
\hline & Immobility (5-s bins) & Climbing (no. of climbs) \\
\hline WKY & & \\
Vehicle & $16 \pm 2$ & $3 \pm 1$ \\
DMI & $5 \pm 1^{* * *}$ & $13 \pm 3^{* * *}$ \\
& & \\
Wistar & & $10 \pm 2^{++}$ \\
Vehicle & $4 \pm 0.5^{++}$ & $11 \pm 2$ \\
DMO & $3 \pm 0.5$ & \\
\hline
\end{tabular}

Forced swim test were carried out on the last 2 days of antidepressant administration, the 5-min posttest being at I h after the last injection. The 5-min posttest scored for immobility (number of 5-s bins spent with floating). Number of climbing events is recorded. Data were derived from seven animals per treatment group. Two-way ANOVA followed by post hoc $t$-test indicated strain differences $\left({ }^{++} p<0.0 \mathrm{I}\right)$ and treatment differences $(* * p<0.0 \mathrm{I})$.

The increased climbing has been observed in animals with noradrenergic deficits that are successfully treated with NET selective antidepressants (Detke et al, 1995). These results are also in accordance with previous data (TejaniButt et al, 2003), which found no change in the behavior of Wistars in response to a variety of antidepressants, including DMI.

\section{Chronic DMI Treatment Alters NET Activity and Sensitivity to Nocodazole Differentially in the WKY and Wistar Strains of Rat}

The neurochemical basis of the behavioral response to DMI treatment in the two strains was examined. Previously we had shown that $\alpha$-Syn modulates the activity and cellular localization of NET, a role that is partially mediated by its interactions with MTs (Jeannotte and Sidhu, 2007). We determined the functional activity of NET in frontal cortex synaptosomes prepared from WKY and Wis rats by examining the ability of the transporters to take up $\left[{ }^{3} \mathrm{H}\right]-$ $\mathrm{NE}$ both before and after treatment of synaptosomes with nocodazole, a MT-destabilizing agent. Our previous studies in cells had shown that the negative modulation of NET by $\alpha$-Syn was completely eliminated upon disruption of $\alpha$-Syn/ MT interactions, resulting in increased uptake of $\left[{ }^{3} \mathrm{H}\right]-\mathrm{NE}$ due to increased trafficking of NET to the cell surface (Jeannotte and Sidhu, 2007). In the current study, treatment of saline-treated WKY synaptosomes with nocodazole did not lead to any increase in $\left[{ }^{3} \mathrm{H}\right]-\mathrm{NE}$ uptake suggesting that the NET in these animals may not be appropriately modulated by $\alpha$-Syn and MTs. In saline-treated Wistar synaptosomes there was a significant increase in NET activity after treatment with $100 \mu \mathrm{M}$ nocodazole (Figure 1a; ${ }^{* *} p<0.01 ; 100$ vs no nocodazole; $\left.n=8\right)$. In synaptosomes from WKY animals treated with DMI, a significant increase $(37 \%)$ in $\left[{ }^{3} \mathrm{H}\right]-\mathrm{NE}$ uptake was observed following treatment with $100 \mu \mathrm{M}$ of nocodazole $\left({ }^{\#} p<0.01, n=8\right)$. Yet, in DMItreated Wistars $100 \mu \mathrm{M}$ nocodazole induced a decrease in $\left[{ }^{3} \mathrm{H}\right]-\mathrm{NE}$ uptake, relative to the saline-treated Wistars at $\left({ }^{\#} p<0.01, n=8\right)$. Unexpectedly, uptake of synaptosomes from saline-treated Wistars was significantly greater than saline-treated WKY rats at all doses of nocodazole
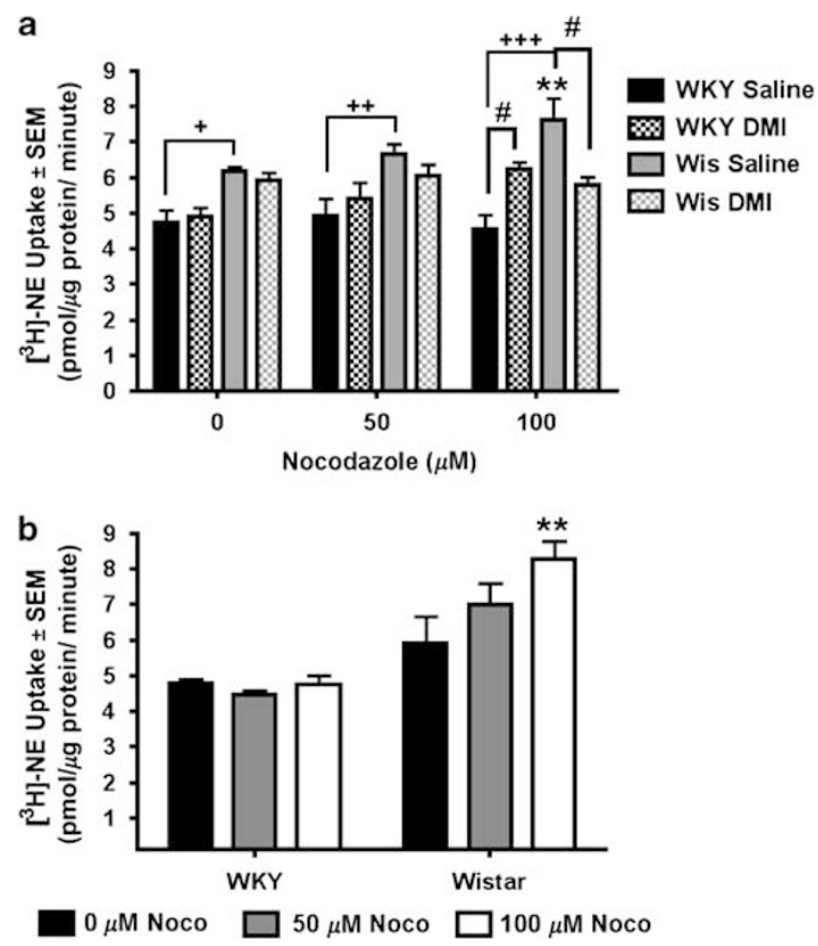

Figure I Chronic, but not acute, desipramine (DMI) treatment in vivo differentially alters norepinephrine transporter (NET) dynamics in WistarKyoto (WKY) and Wistar synaptosomes. (a) Synaptosomes from the frontal cortex of saline- or DMl-treated WKY and Wistar rats were treated with nocodazole $(0,50$, or $100 \mu \mathrm{M})$ and $\left[{ }^{3} \mathrm{H}\right]$-NE uptake was measured. Data represent eight individual animals, with each point averaged from samples run in triplicate. I $\mu \mathrm{M} \mathrm{DMI}$ was added during the uptake to determine nonspecific uptake, this was then subtracted from the data. ${ }^{+} p<0.05,{ }^{+}{ }^{+} p<0.01,{ }^{++}{ }^{+} p<0.001$ saline WKY vs saline Wis; ${ }^{*} p<0.01$ vs no nocodazole in Wis saline, ${ }^{\#} p<0.0$ l saline vs DMI (ANOVA, Bonferroni). (b) Animals were given a single injection of DMI, killed $24 \mathrm{~h}$ later, processed, and assayed as in Figure 3. Data represent the average of six animals, with each point averaged from triplicates. Data were analyzed using two-way ANOVAs with a Bonferroni post hoc analysis if $p<0.05$. *** $p<0.0$ I vs no nocodazole.

$\left({ }^{+} p<0.05,{ }^{++} p<0.01,{ }^{++} p<0.001, n=8\right)$. It would be expected that with a greater depressive-like phenotype the WKY rats would show a greater amount of NE uptake; however, these results may suggest an overall lower basal noradrenergic activity in the WKY or involvement of the serotonergic system in the development of their phenotype. Although we did not directly test the kinetics of uptake in this study, previously frontal cortex synaptosomes from SD rats were treated with nocodazole and an increase in $V_{\max }$ was observed, without a change in $K_{\mathrm{m}}$, relative to vehicle-treated synaptosomes (Jeannotte and Sidhu, 2007). Similar studies in the WKY and Wistar rodents treated with saline or DMI would clarify the mechanism underlying the change in NET activity following nocodazole treatment.

To test whether the uptake results of Figure 1a could be due to desensitization of the transporter attributable to an acute effect of DMI, a single dose of DMI was administered to both WKY and Wistar rats (Figure 1b). At $24 \mathrm{~h}$ following the single injection, synaptosomes were prepared and uptake measured following nocodazole treatment. The results mimicked those found in saline-treated WKY and 
Wistar animals (Figure $1 \mathrm{a}$ and $\mathrm{b} ;{ }^{* *} p<0.01, n=6$ ). Thus, changes in $\left[{ }^{3} \mathrm{H}\right]-\mathrm{NE}$ uptake in response to nocodazole treatment were only seen after chronic, not acute, administration of the antidepressant.

The above findings were further confirmed by $\left[{ }^{3} \mathrm{H}\right]-\mathrm{NSX}$ used to determine the kinetics of NET binding to quantify total transporters in the synaptosomal preparations. Both $K_{\mathrm{d}}$ and $B_{\max }$ values in saline-treated WKYs and Wistars were similar (Supplementary Figure S1A and B; Supplementary Table $S 1 ; n=8)$. After chronic DMI treatment, total NET binding $\left(B_{\max }\right)$ significantly decreased in DMI-treated animals, without a concomitant large decrease in $K_{\mathrm{d}}$ (Supplementary Figure S1A and B; Supplementary Table $\mathrm{S} 1 ;{ }^{\star *} p<0.01$ vs saline; $\left.n=8\right)$. The changes in binding are consistent with a decrease in $V_{\max }$ of NET transport seen in hippocampal and frontal cortex synaptosomes in rodents chronically treated with antidepressants (Benmansour et al, 2004). These findings suggest that DMI treatment did not alter the affinity of binding, but rather caused a decrease in NET binding sites in the frontal cortex, consistent with results in other reports using chronically injected DMI (Lee et al, 1983).

\section{Chronic DMI Alters Protein Levels and Cellular Localization of NET in the Frontal Cortex}

The expression level and cellular distribution of total NET in WKY and Wistar frontal cortex lysates were examined (Figure 2a). These lysates were additionally subfractionated into plasma membrane (Figure 2b) and intracellular cytosolic fractions (Figure 2c) to examine potential changes in the cellular distribution of NET. The lysate and plasma membrane fractions show a double protein band corresponding to the higher molecular weight of NET ( $\sim 75$ and $80 \mathrm{kDa}$ ), possibly representing different glycosylated forms of the protein (Melikian et al, 1994). In the WKY lysate fraction total NET expression decreased, though not significantly, following DMI treatment (Figure 2a). NET protein was significantly downregulated in DMItreated Wistar rats, compared to their saline-treated strain counterparts $\left(31 \% ;{ }^{*} p<0.01, n=6\right)$. Interestingly, the overall expression level of NET was lower in the WKYs compared to the Wistar rats regardless of treatment, and this may account for the lower NET activity and binding seen in these rats (Figure 1; Supplementary Figure S1). The change in total NET levels in lysates upon DMI treatment was accompanied by a significant decrease in plasma membrane-associated NET in both strains (Figure 2b; $\left.{ }^{* *} p<0.01,{ }^{* *} p<0.005, n=6\right)$. However, in the WKY, the decrease in membrane NET (9\%) was compensated for by an increase in intracellular levels of NET, likely representing increased trafficking of the transporter away from the cell surface and into the cytosol (Figure $2 c ; 11 \%$; ${ }^{* *} p<0.01$, $n=6)$. In contrast, DMI-treated Wistars had a significant reduction in cytosolic levels of NET (Figure 2c; 13\%; $\left.{ }^{* * *} p<0.005, n=6\right)$.

\section{The Expression of Other Monoamine Transporters is not Affected by Chronic DMI Treatment}

Several studies have found that DMI alters the expression and binding of both the serotonin and dopamine transpor-
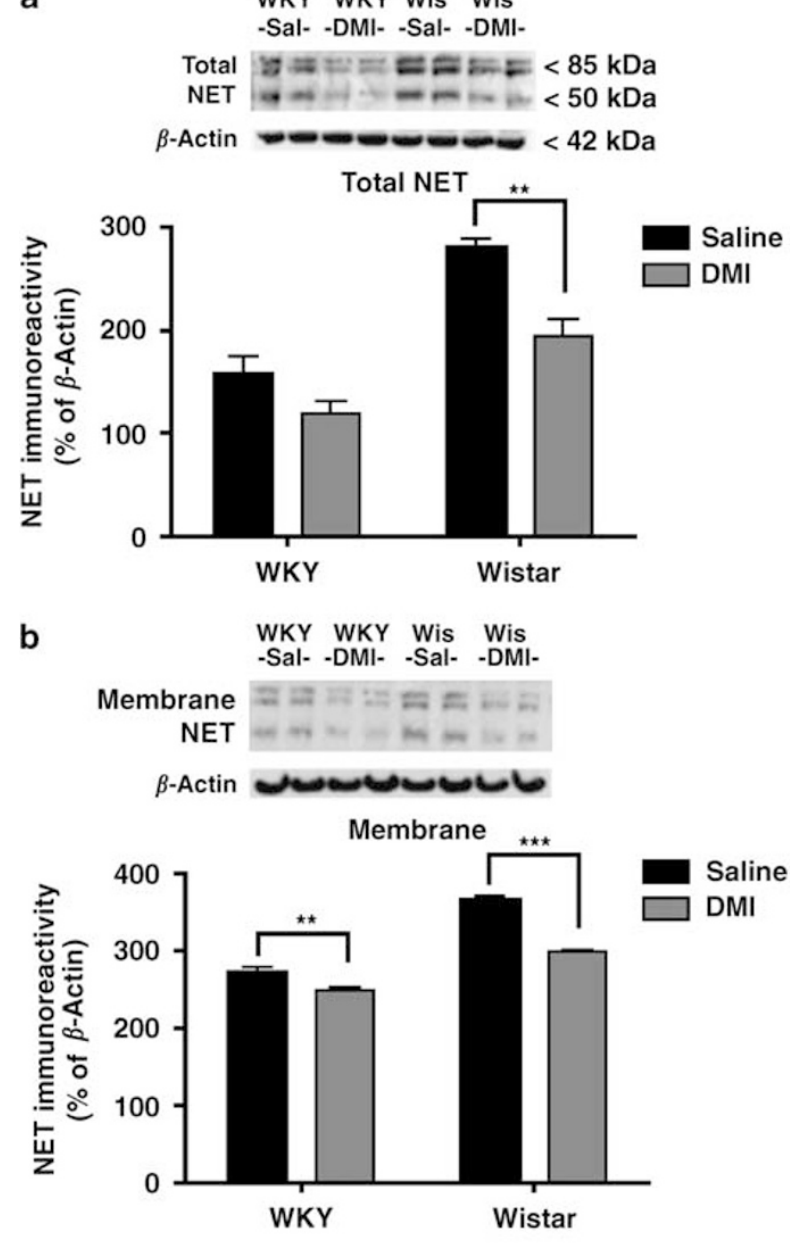

WKY WKY Wis Wis
-Sal- -DMI- -Sal- -DMI-
Cytosolic
NET
$\beta$-Actin

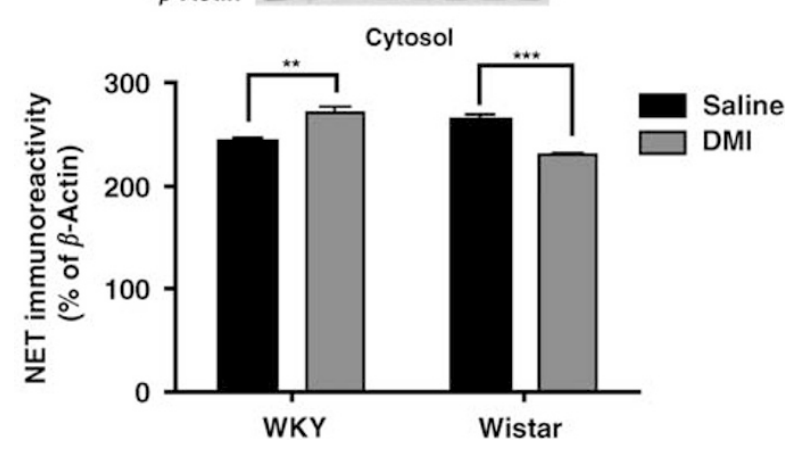

Figure 2 Norepinephrine transporter (NET) expression and compartmentalization is altered in response to desipramine (DMI). Frontal cortex tissue was analyzed for the expression of total (a), plasma membrane (b), and intracellular cytosolic (c) NET. Samples were prepared as described in 'Materials and methods'. Expression of each sample was normalized to $\beta$-actin and then averaged from six individual animals. Each blot is the best representative image of two individual samples from each treatment group. Two-way ANOVA with a threshold of $p<0.05$ set for statistical significance, Bonferroni post hoc, *** $p<0.01$, **** $p<0.005$.

ters (SERT and DAT, respectively; reviewed in Frazer, 1997). The protein expression of both transporters was lower in the Wistar strain of rats, compared to the WKY 
(Supplementary Figure S2A and B; ${ }^{\star} p<0.05,{ }^{*} p<0.01$, $n=5$ ). However, there was no significant effect of the drug on antidepressant $v s$ saline-treated animals of the same strain and changes in SERT or DAT expression were not seen. This finding suggests that although differences in the expression of SERT and DAT may contribute to underlying strain differences between WKY and Wistar, it does not explain the change in NET activity and its altered dependence on the MT network, after treatment with DMI.

Chronic DMI Treatment Alters the Expression of $\alpha$ - and $\gamma$-Syn, but not $\beta$-Syn in the Frontal Cortex

$\alpha$-Syn expression levels and its cellular distribution in both rodent strains were also examined before and after DMI treatment. Total $\alpha$-Syn levels increased (50\%) in DMItreated WKY rats relative to saline-treated animals of the same strain (Figure 3a; ${ }^{* *} p<0.005, n=6$ ). There were no significant changes in $\alpha$-Syn expression in antidepressanttreated Wistars compared to saline controls. The same trend continued in the membrane-bound $\alpha$-Syn with an increase (25\%) observed in these fractions (Figure $3 \mathrm{~b}$; ${ }^{*} p<0.05$, $n=6)$. However, the inverse was observed in cytosolic $\alpha$ Syn, where WKY rats treated with DMI had significantly lower levels $(16 \%)$ of $\alpha$-Syn in the cytosol (Figure 3c; ${ }^{*} p<0.05, n=6$ ). In contrast, in the Wistar rat, $\alpha$-Syn levels were significantly higher $(26 \%)$ in the cytosol compared to saline-treated rats (Figure $3 c ;{ }^{*} p<0.05, n=6$ ).

We next examined levels of the other synucleins. $\beta$-Syn levels were not significantly altered by DMI treatment in either the WKY or the Wistar rat (Figure 4). This synuclein subtype was found in total lysates and cytosolic fractions (Figure $4 \mathrm{a}$ and $\mathrm{c}$, respectively), but was notably absent from membrane fractions (Figure $4 \mathrm{~b}$ ). This indicates that $\beta$-Syn has very different properties than $\alpha$-Syn with regard to membrane associations and that it may not be involved in the regulation of NET function (also see Figure 8).

Most interestingly, total $\gamma$-Syn expression in salinetreated WKY tissue was much higher (37\%) than that in Wistar rats (Figure $5 \mathrm{a} ; p<0.01, n=6$ ). However, following DMI treatment, the total levels of $\gamma$-Syn were decreased (20\%) in WKY (Figure 5a), with lower amounts of the protein seen at the membrane (Figure $5 \mathrm{~b} ;{ }^{\star} p<0.05, n=6$ ). By contrast, in the Wistar rat, DMI caused an increase $(25 \%)$ in total $\gamma$-Syn levels (Figure 5a), which was accompanied by increased localization of the protein at the membrane (Figure $5 \mathrm{~b} ;{ }^{\star} p<0.05, n=6$ ). There were no significant changes in the intracellular amounts of $\gamma$-Syn in either the WKY or the Wistar rat (Figure $5 c ; n=6$ ). These combined data of $\alpha-, \beta$-, and $\gamma$-Syn indicate that at the neurochemical level, the effect of DMI may be related to altered expression levels and cellular localization of these synuclein proteins.

Protein associations between NET, synucleins, and tubulins are differentially altered by chronic DMI treatment in both the WKY and Wistar rats

Protein-protein interactions were tested by reciprocal coimmunoprecipitations (IPs) between NET and $\alpha$ - and $\gamma$-Syn. These assays were conducted in frontal cortex a

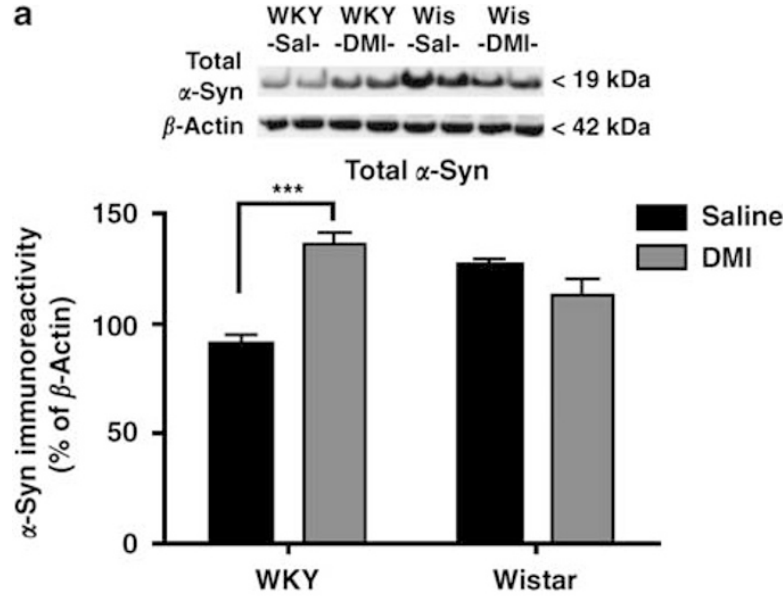

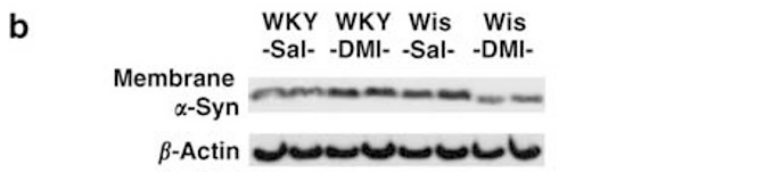

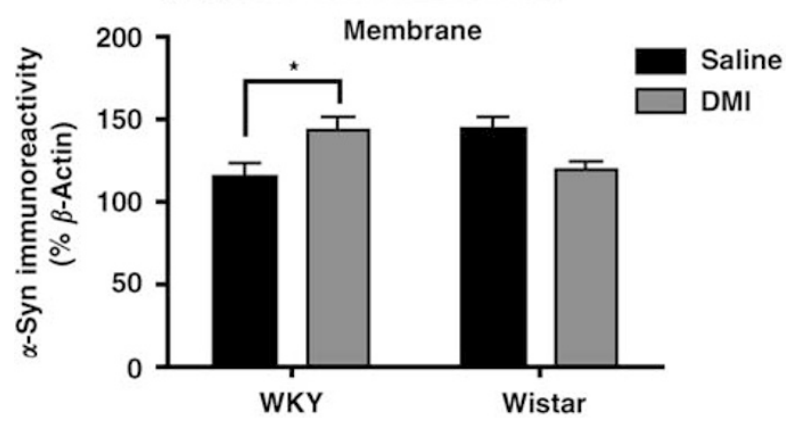

C
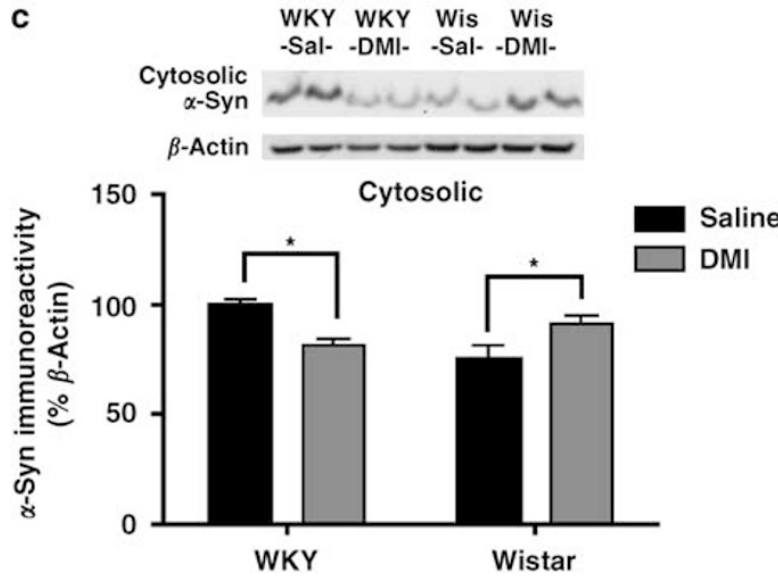

Figure $3 \alpha$-Synuclein ( $\alpha$-Syn) expression and compartmentalization is altered in response to desipramine (DMI). Frontal cortex tissue was analyzed for the expression of total (a), plasma membrane (b), and intracellular cytosolic (c) $\alpha$-Syn. Samples were prepared as described in 'Materials and methods'. Expression of each sample was normalized to $\beta$ actin and then averaged from six individuals animals. Each blot is the best representative image of two individual samples from each treatment group. ANOVA analysis with a threshold of $p<0.05$ set for statistical significance. * $p<0.05$, **** $p<0.005$ (Bonferroni)

homogenates to determine if DMI treatment alters protein complexes that may form between these proteins (Figure 6). IPs with NET antibodies suggested that interactions of the transporter with $\alpha$-Syn were increased in the frontal cortex 

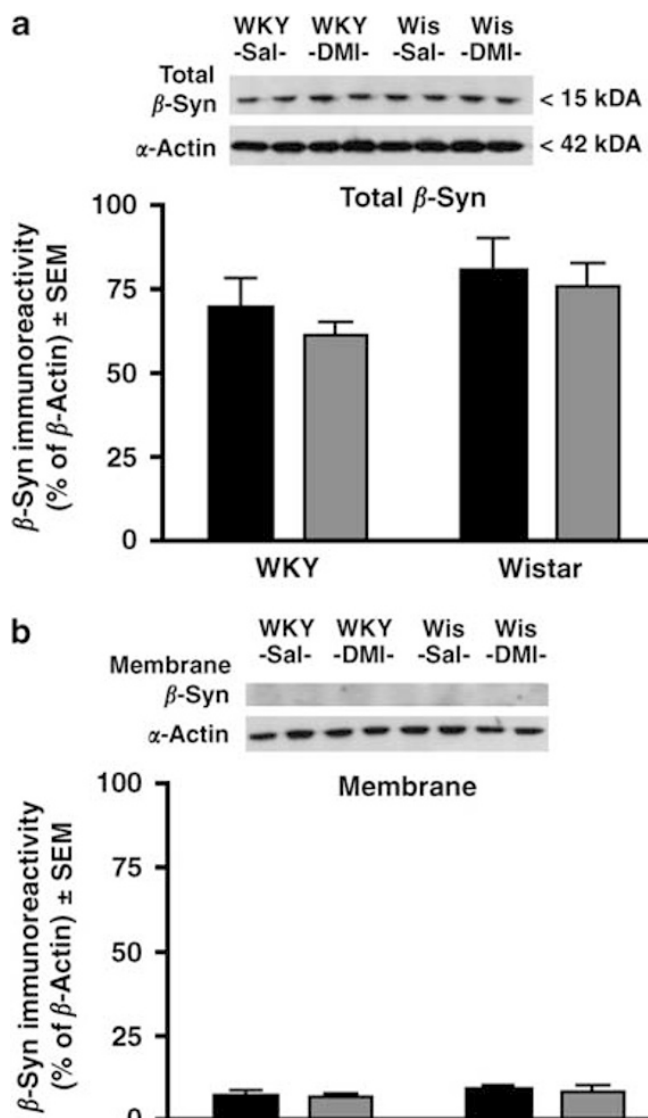

C
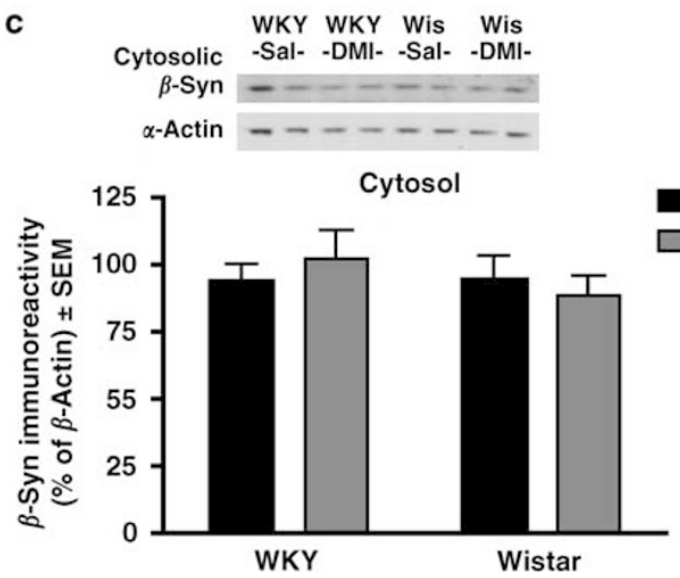

Figure $4 \quad \beta$-Synuclein ( $\beta$-Syn) expression and compartmentalization is not altered in response to desipramine (DMI). Frontal cortex tissue was analyzed for the expression of total (a), plasma membrane (b), and intracellular cytosolic (c) $\beta$-Syn. Samples were prepared as described in 'Materials and methods'. Expression of each sample was normalized to $\beta$ actin and then averaged from four individual animals. Each blot is the best representative image of two individual samples from each treatment group.

of WKYs following DMI treatment, but were decreased in DMI-treated Wistars (Figure 6a). Moreover, NET antibodies coimmunoprecipitated lower levels of $\gamma$-Syn in frontal cortex homogenates from the drug-treated WKYs relative to their saline-treated counterparts. The IPs using $\alpha$ - or $\gamma$-Syn antibodies revealed similar changes in NET associations with these proteins after DMI treatment (Figure 6b and c). Using either of the synuclein antibodies for the a

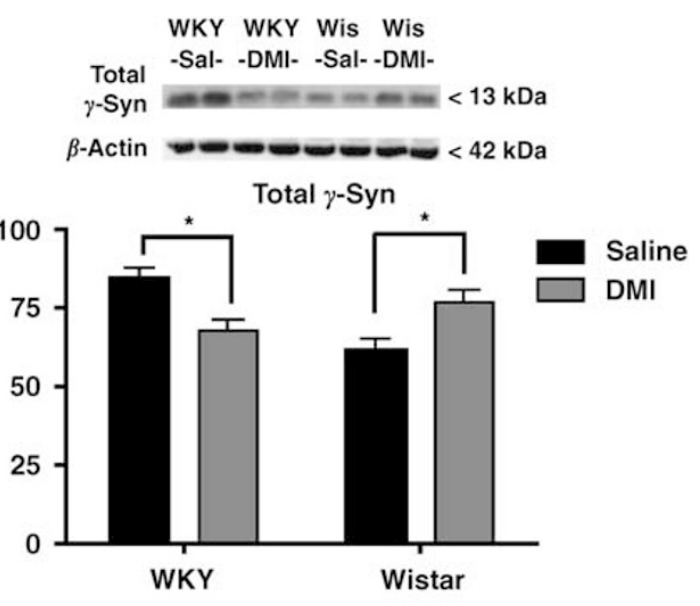

b

WKY WKY Wis Wis Membrane -Sal- -DMI- -Sal- -DMI$\gamma$-Syn $-\infty-\infty-\infty=$
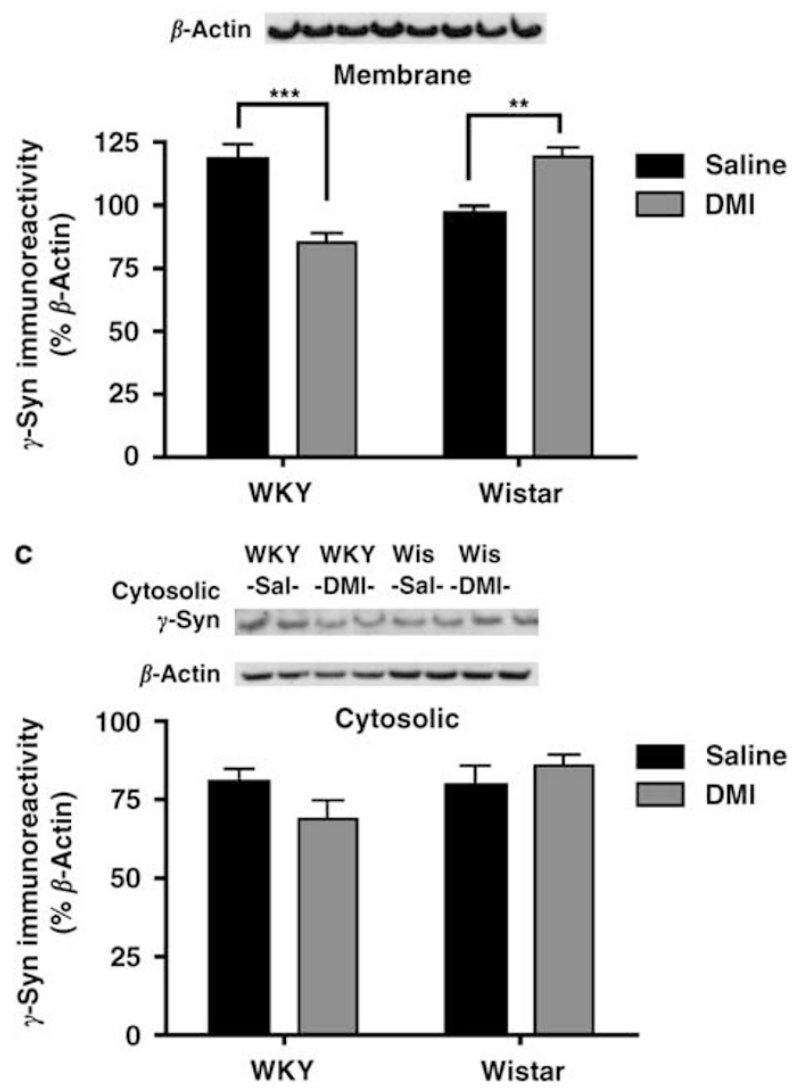

Figure $5 \quad \gamma$-Synuclein ( $\gamma$-Syn) expression and compartmentalization is altered in response to desipramine (DMI). Frontal cortex tissue was analyzed for the expression of total (a), plasma membrane (b), and intracellular cytosolic (c) $\gamma$-Syn. Samples were prepared as described in 'Materials and methods'. Expression of each sample was normalized to $\beta$ actin and then averaged from six individual animals. Each blot is the best representative image of two individual samples from each treatment group. Two-way ANOVAs with a threshold of $p<0.05$ set for statistical significance, Bonferroni post hoc analysis, $* p<0.05$, *** $p<0.0$ I, **** $p<0.005$.

precipitation, protein-protein interactions between $\alpha$ - and $\gamma$-Syn were found to be low, attesting to the specificity of these antibodies and lack of cross-reactivity between the proteins (Figure $6 \mathrm{~b}$ and $\mathrm{c}$, respectively). Probing the blots 


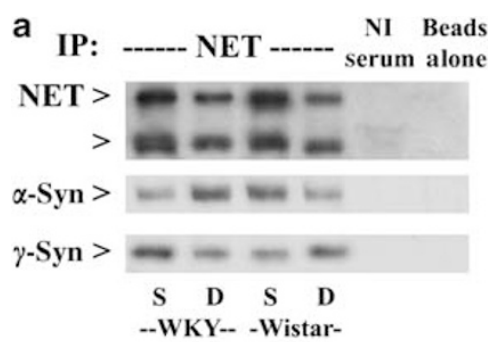

b IP: ----- $\alpha$-Syn ----- NI Beads

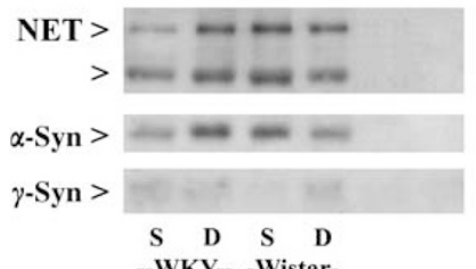

--WKY-- -Wistar-

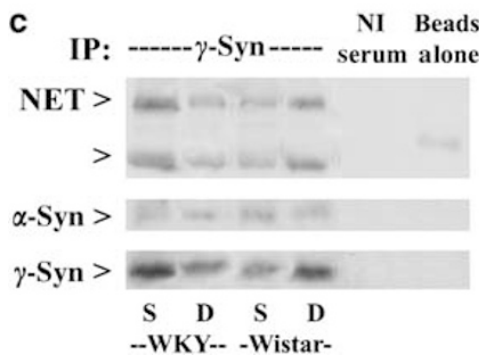

Figure 6 Protein interactions between norepinephrine transporter (NET), $\alpha$-, and $\gamma$-Syn are altered by desipramine (DMI) treatment. Frontal cortex tissue was prepared as described in 'Materials and methods' from saline (S) or DMI- (D) treated Wistar-Kyoto (WKY) or Wistar rats. Immunoprecipitations were performed using the polyclonal antibodies of rabbit-anti-NET (a) rabbit-anti- $\alpha$-Syn (b), and sheep-anti- $\gamma$-Syn (c). Control immunoprecipitations were performed using nonimmune serum $(\mathrm{NI})$ and protein A/G beads (beads alone). SDS-PAGE was used to analyze the proteins and membranes were probed using anti- $\alpha$-Syn, $\gamma$-Syn, and NET antibodies. Each coimmunoprecipitation was performed on tissue from six individual animals. Pictures are the best representative image from each condition.

with $\alpha$-Syn antibodies confirmed increased expression of $\alpha$-Syn in WKYs treated with DMI and Wistars administered saline (Figure $6 \mathrm{~b}$ ). Similarly, changes in $\gamma$-Syn immunoreactivity after using a $\gamma$-Syn antibody to pull-down complexes mirrored its relative decreased or increased expression in DMI-treated WKYs or Wistars, respectively (Figure 6c). Nonimmune sera (NI serum) or protein A/G beads (beads alone) were used as controls in co-IP assays to determine the degree of nonspecific binding, which was almost undetectable or not present (Figure $6 \mathrm{a}-\mathrm{c}$ ).

Separately, the interactions of both $\alpha$ - and $\beta$-tubulins with NET, $\alpha$-, or $\gamma$-Syn were tested. Co-IPs were performed using $\gamma$-Syn or NET (Figure 7a) and $\alpha$-Syn or NET (Figure 7b) antibodies. When the pull-down was performed with $\gamma$-Syn antibodies there was a slight decrease in interactions of this protein with both tubulins in DMI-treated WKY compared to saline-treated WKY rats. In contrast there was a noticeable increase in protein complexes formed between $\gamma$-Syn and $\alpha$ - and $\beta$-tubulins, after DMI treatment of Wistars, compared to their saline-treated strain counterparts (Figure 7a). A pulldown with $\alpha$-Syn antibodies, revealed interactions between a

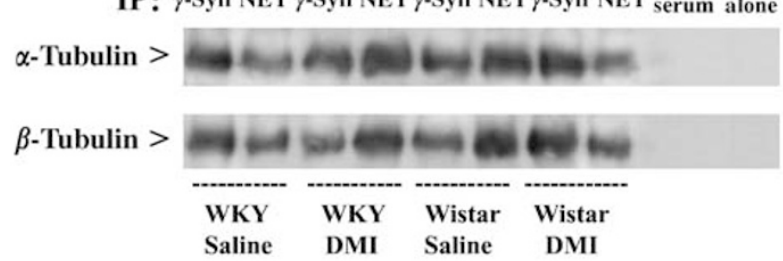

b

b IP. $\alpha$-Syn NET $\alpha$-Syn NET $\alpha$-Syn NET $\alpha$-Syn NET NI Beads $\alpha$-Tubulin >

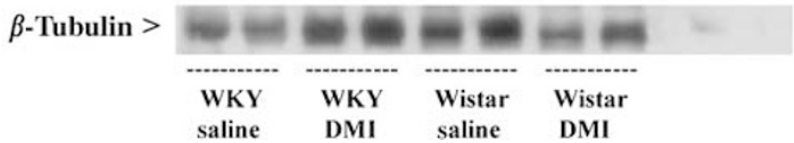

Figure $7 \alpha$-and $\beta$-tubulin interactions with norepinephrine transporter (NET), $\alpha$-, and $\gamma$-synuclein (Syn) are altered in response to chronic desipramine (DMI) treatment. Frontal cortex tissue was prepared from saline- or DMI-treated Wistar-Kyoto (WKY) or Wistar animals. Coimmunoprecipitations were performed using rabbit-anti- $\gamma$-Syn and rabbit-antiNET (a) and sheep-anti- $\alpha$-Syn and NET (b). Control immunoprecipitations were performed using nonimmune serum $(\mathrm{NI})$ and protein $\mathrm{A} / \mathrm{G}$ beads (beads alone). Proteins were resolved using SDS-PAGE and immunoblotted using monoclonal antibodies anti- $\alpha$-tubulin and anti- $\beta$-tubulin. Each assay was performed on tissue isolated from six individual animals and the data represent the best representative image from two animals in each treatment and strain pairing groups.

$\alpha$-Syn and $\alpha$ - and $\beta$-tubulins in saline-treated WKYs, these were found to be lower relative to those seen in the WKY after chronic treatment with DMI. The inverse occurred in Wis rats, whereby DMI treatment appeared to cause a decrease in protein-protein interactions between $\alpha$-Syn and both tubulins (Figure $7 \mathrm{~b}$ ). NET associations with tubulins were increased following DMI treatment of the WKY, but decreased following similar treatment of Wistars, compared to their respective saline-treated counterparts.

Together, these co-IP data suggest that following changes in protein expression, there may be a shift in the interactions between the synucleins, NET, and the tubulins, which could underlie the improvement in depressive behavior seen in the WKY rat following chronic DMI treatment. These findings suggest that DMI targets the synuclein-mediated regulation of NET activity and cellular localization in vivo.

\section{$\alpha$-Syn, but not $\beta$ - or $\gamma$-Syn Modulation of NET, is Eliminated by Depolymerizing the MT Cytoskeleton}

In view of the above findings, we further investigated the effect of $\gamma$-Syn and $\beta$-Syn on NET function and sensitivity to nocodazole in $\mathrm{L} t k$ - cells co-transfected with synucleins and NET. Cells were transfected with a constant amount of NET $(1 \mu \mathrm{g} / \mathrm{ml} \mathrm{DNA})$ and increasing amounts of the synuclein subtypes $(0-3 \mu \mathrm{g} / \mathrm{ml} \mathrm{DNA})$, and functional studies were conducted before and after treatment with nocodazole, as described under 'Materials and methods'. Untreated cells co-transfected with increasing amounts of $\alpha$-Syn and NET DNA had an increase in $\left[{ }^{3} \mathrm{H}\right]-\mathrm{NE}$ uptake at low expression levels of $\alpha$-Syn $(0.5 \mu \mathrm{g} / \mathrm{ml} \mathrm{DNA})$, followed by a significant decrease in $\left[{ }^{3} \mathrm{H}\right]$-NE uptake in cells expressing $>3 \mu \mathrm{g} / \mathrm{ml}$ of 


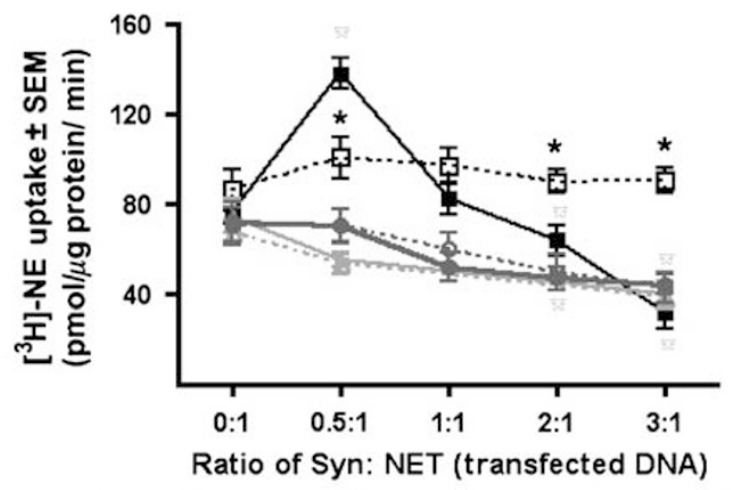

$$
\begin{aligned}
& \rightarrow \alpha \text {-Syn - Noco }-\beta \text {-Syn - Noco } \rightarrow \gamma \text {-Syn - Noco } \\
& \text { 曰- } \alpha \text {-Syn + Noco } \cdots \cdot \cdot \beta-S y n+\text { Noco } \cdot \cdot \cdot \cdot \gamma-\operatorname{Syn}+\text { Noco }
\end{aligned}
$$

Figure $8 \quad \beta$ - and $\gamma$-synuclein (Syn)-mediated regulation of $\left[{ }^{3} \mathrm{H}\right] \mathrm{NE}$ uptake is insensitive to treatment with nocodazole. $\mathrm{Ltk}^{-}$fibroblasts were transiently transfected as described in 'Materials and methods' section, with either norepinephrine transporter (NET) alone $(0:$ I) or $0.5-3 \mu \mathrm{g} / \mathrm{ml}$ of $\alpha$ or $\gamma$-Syn and $\mathrm{I} \mu \mathrm{g} / \mathrm{ml}$ of NET. Cells were either treated with vehicle $(0.01 \%$ DMSO) or $100 \mu \mathrm{M}$ nocodazole in serum-free media. Averages were calculated from six experiments performed in triplicate \pm SEM (ANOVA, Bonferroni).

$\alpha$-Syn, compared to cells transfected with NET alone (Figure 8), consistent with our previous studies (Wersinger et al, 2006a; Jeannotte and Sidhu, 2007). Following treatment with $100 \mu \mathrm{M}$ of nocodazole for $1 \mathrm{~h}$, the increase in NET activity seen at low levels of $\alpha$-Syn was relieved, and NET function was similar to that of untreated, control cells not expressing any $\alpha$-Syn. In addition, nocodazole also relieved the inhibition seen upon increased levels of $\alpha$-Syn.

In cells co-transfected with increasing amounts of $\gamma$-Syn and $\beta$-Syn, there was also a progressive decrease in $\left[{ }^{3} \mathrm{H}\right]-\mathrm{NE}$ uptake upon increased expression levels of these synucleins (Figure 8). Most remarkably, however, treatment with nocodazole did not reverse the inhibitory effects of these proteins. These findings in vitro suggest that $\alpha$-Syn modulation of NET is dependent on interactions with MTs, whereas $\beta$ - and $\gamma$-Syn modulation of NET is likely mediated by other cytoskeletal structures or cellular proteins. However, the possibility remains that $\beta$ - and $\gamma$ Syn-mediated modulation of NET also proceeds by interactions with MTs, but for reasons unknown, $\beta$ - or $\gamma$-Syn and cytoskeleton interactions are much more resistant to destabilizing agents. These data also support the findings by other groups that higher $\gamma$-Syn expression is correlated with increased cellular resistance to MT-destabilizing drugs (Ji et al, 1997; Wu et al, 2003).

\section{DISCUSSION}

We have shown here that DMI treatment caused a decrease in NET and $\gamma$-Syn protein levels and an increase in the expression of $\alpha$-Syn in the WKY, a rat strain widely studied for its innate depressive-like behavior. This is the first report of the pathophysiological involvement of any member of the synuclein family in the genesis of depression. It is also the first report of antidepressants modulating the expression of any of the synuclein proteins. Moreover, we have shown that the basal expression of $\gamma$-Syn was high in the frontal cortex of the WKY displaying a depressive-like phenotype compared to the Wistar rat. After treatment with DMI, the expression of $\gamma$-Syn was decreased in frontal cortex of the WKY. This finding was unexpected and suggests that $\gamma$-Syn may be important in the pathophysiology of depression. We also found lower levels of $\alpha$-Syn in the frontal cortex of WKY relative to Wistar rats, which was increased following DMI. Taken together this is the first demonstration of abnormal synuclein expression in a model of a mood disorder, revealing a potential mechanism for the trafficking and regulation of NET by synucleins in response to antidepressants.

In addition to changes in protein levels, $\left[{ }^{3} \mathrm{H}\right]-\mathrm{NE}$ uptake, binding, and NET protein interactions were altered in DMItreated animals. In particular, in the saline-treated WKY rats, $\left[{ }^{3} \mathrm{H}\right]-\mathrm{NE}$ uptake was remarkably resistant to modulation by nocodazole, a MT destabilizer that was previously shown to disrupt $\alpha$-Syn-mediated modulation of NET and DAT by interactions with MTs (Jeannotte and Sidhu, 2007; Wersinger and Sidhu, 2005). These findings suggest that either NET is not associated with the MTs in synaptosomes from the WKY rat, or that this interaction is somehow resistant to MT destabilization. In support of the former suggestion, the co-IP studies in the saline-treated WKYs indicated lower amounts of NET associated with $\alpha$ - and $\beta$ tubulins. However, in DMI-treated WKY rats an increase in $\left[{ }^{3} \mathrm{H}\right]-\mathrm{NE}$ uptake was observed in synaptosomes treated with $100 \mu \mathrm{M}$ nocodazole. Moreover, protein complexes between tubulin and NET were increased in this strain after DMI treatment, suggesting that underlying the change in nocodazole sensitivity were the enhanced interactions between these proteins. Furthermore, $\gamma$-Syn interactions with the tubulins were decreased after DMI treatments in the WKY rat, whereas $\alpha$-Syn/tubulin complexes were increased, as indicated by co-IPs. However, these results are not quantitative and must be interpreted with caution, and in the future corroborated using other methods. Yet, such observations are important within the context of our in vitro studies (Figure 8), where $\gamma$-Syn, but not $\alpha$-Syn, regulation of $\left[{ }^{3} \mathrm{H}\right]-\mathrm{NE}$ uptake was found to be insensitive to nocodazole treatments. Taken together, these data suggest that NET sensitivity to nocodazole treatment in salinetreated WKYs could be due to its activity and trafficking being primarily regulated by $\gamma$-Syn, rendering such regulatory functions insensitive to the effects of nocodazole. Upon DMI treatment, a decrease in $\gamma$-Syn levels accompanied by an increase in $\alpha$-Syn levels with restoration of nocodazole sensitivity, suggests that after chronic DMI treatment NET trafficking is under the regulation of $\alpha$-Syn. This is supported by the changes in the expression levels of each of the two synucleins following DMI treatment suggesting that expression of these proteins may be central to their regulation of NET (Figure 9). Indeed, when the expression levels of $\alpha$-Syn and $\gamma$-Syn were analyzed and expressed as ratios, a ratio of 2.06 was obtained in the frontal cortex of saline-treated Wistar compared to 1.07 in the WKY. DMI treatment altered these ratios to 1.50 and 2.01 in Wistar and WKY, respectively. Thus, the altered regulation of NET in the frontal cortex in WKY may in part be due to an initially higher expression of $\gamma$-Syn and lower expression of $\alpha$-Syn, which are normalized after DMI treatment. 


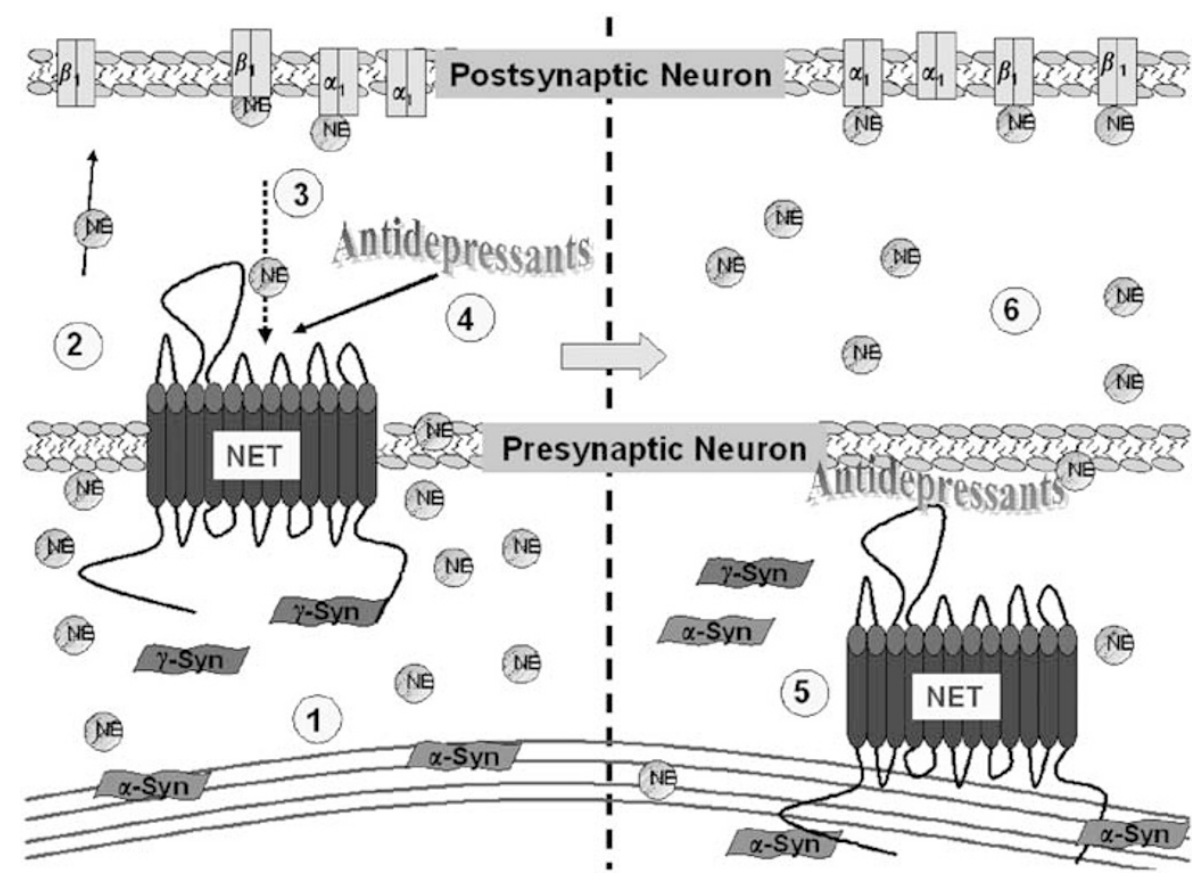

Figure 9 Synuclein (Syn) modulation of norepinephrine transporter (NET) in depression and after treatment with desipramine (DMI). (I) In the WistarKyoto (WKY) rat, $\gamma$-Syn expression is high, whereas $\alpha$-Syn expression is low. NET activity is insensitive to nocodazole treatment; however, it forms protein interactions with tubulins. This suggests that $\gamma$-Syn mediates the activity and trafficking of the transporter. (2) NE gets released into the synapse, diffuses across the synapse and can bind to pre- or postsynaptic receptors. (3) NE is either degraded in the synaptic cleft or taken back up into the presynaptic terminal through NET. (4) This transport activity is directly blocked by DMI, or other antidepressants. (5) Following chronic treatment of the WKY with DMI, a NET-selective antidepressant, $\gamma$-Syn expression decreases, $\alpha$-Syn is redistributed from the cytosol to membrane fractions, and NET activity is sensitive to nocodazole treatment. This suggests that $\alpha$-Syn-mediated regulation of NET by interactions with MTs is restored by DMI treatment. (6) NE is released into the synapse where it can remain active and increase the chances of binding both pre- and postsynaptic receptors due to a decrease in the surface expression of NET.

In both the WKY and Wistar, the cytoskeleton-mediated regulation of NET activity and its surface expression were differentially affected by the physiology underlying depressive-like behavior, as well as subsequent antidepressant treatment. Nocodazole-resistant interactions between the transporter and MTs could indicate that NET delivery to the synaptic terminal, trafficking to the plasma membrane, and subsequent internalization and degradation are dysregulated in depression. More generally, these findings suggest that other MT-mediated activities at the synapse may also be altered in this animal model of depression. Potential, but as yet unstudied, functions may include vesicle release, vesicle recycling, delivery of mitochondria to the synaptic terminal, internalization of surface receptors, and degradation of old or misfolded proteins. These data highlight a previously underappreciated involvement for the MT cytoskeleton in mediating the cellular response to DMI. To this end, one study chronically treated Wistar rats with DMI and found a reduction in the assembly of MTs in the cortex (Miyamoto et al, 1997). This finding could explain the loss of sensitivity to nocodazole, without an induction of depressive-like behavior, in the cohort of Wistars treated with DMI in the current study; thus, the MTs are already at a lower rate of polymerization and would not be changed by further destabilization using nocodazole.

At the neurochemical level, there was a modest increase in total and membrane-bound $\gamma$-Syn levels in the Wistar strain, whereas the opposite was true for the WKY rats. DMI also increased cytosolic levels of $\alpha$-Syn in the Wistar, whereas decreasing $\alpha$-Syn levels in cytosol of WKY rats. Such changes are reflected by the fact that the ratio of $\alpha$ Syn : $\gamma-$ Syn in Wistar rats was reduced to 1.50 , but failed to reach the lower ratio seen in WKY (1.07), suggesting that a ratio of 1.50 may be sufficient to see nocodoazole resistance, but not depressive behavior.

In addition to changes at the protein level, DMI may also directly affect the trafficking of NET. DMI alters the composition of lipid rafts, a primary mechanism for delivering and removing proteins from the cellular surface (Donati and Rasenick, 2005), which potentially affects the manner in which NET is integrated in the plasma membrane. NET phosphorylation and internalization, as well as $\alpha$-Syn-mediated endocytosis of transmembrane proteins, occurs by lipid rafts (Fortin et al, 2004; Jayanthi et al, 2004; Kubo et al, 2005). Therefore, chronic DMI treatment could alter synuclein and NET interactions at the membrane, especially those between $\gamma$-Syn and NET, based on our findings on opposing changes in membrane levels of $\gamma$-Syn (Figure 5). Indeed, increased $\gamma$-Syn/NET associations at the plasma membrane in the Wistar rat may also account for the resistance to nocodazole seen in these animals, whereas the opposite is true for the DMI-treated WKY rats. Although it is unknown how $\gamma$-Syn participates in chaperoning events and membrane interactions, $\gamma$-Syn has been shown to enhance estrogen receptor trafficking to the cell surface (Liu et al, 2007). DMI is also known to disrupt membranes (Fisar et al, 2005; Santos et al, 2004). Therefore, the upregulation of $\alpha$-Syn in the WKY, which itself can 
directly associate with membranes (Davidson et al, 1998; Fortin et al, 2004; Jensen et al, 1998; Kubo et al, 2005) may act to promote trafficking of NET away from the cell surface. The ability of $\alpha$-Syn to traffic NET is consistent with previously reported chaperone activities of $\alpha$-Syn (Bonini and Giasson, 2005; Chandra et al, 2005; Ostrerova et al, 1999). Overall, our findings indicate that DMI not only affects synuclein protein expression, but may also induce changes in their biochemical interactions with the membrane, thereby impacting the chaperoning and/or trafficking of NET.

These findings add further complexity to the cellular roles of the synucleins. They establish a differential role for $\alpha$ and $\gamma$-Syn in homeostasis and disease, a distinction that was previously only made for one disease state, primarily PD, and also certain cancers and glaucoma. This work suggests that changes in these two proteins can also contribute to depression pathology due to their regulatory effects on NET. As $\gamma$-Syn is upregulated in the frontal cortex in animals displaying depressive-like symptoms, although the $\alpha$-Syn expression is low, a similar mechanism could occur in $\mathrm{PD}$ where it has been found that $\alpha$-Syn bioavailability is reduced due to its propensity to form fibrils and aggregate. The high proportion of PD patients affected by depression suggests that in this subset of affected individuals there may be a common etiology, which may also indicate a common treatment or prevention strategy. Taken in conjunction with the results shown here, the high incidence of comorbidity of $\mathrm{PD}$ and depression in human patients suggests that both basic and clinical studies need to be performed to determine the mechanism and long-term impact of DMI and other antidepressants on PD populations.

\section{ACKNOWLEDGEMENTS}

We thank Jacqueline Reindl for her aid in revising this publication. This work was made possible by the grants F31 MH76612 (to AMJ) and R01MH075020 and R01AG028108 (to AS) awarded by the National Institutes of Health and the Davee Foundation (to EER).

\section{DISCLOSURE/CONFLICT OF INTEREST}

All authors have no conflict of interest or information to disclose concerning any of the companies, products, devices, or findings used in obtaining the reported results or described in this manuscript. The authors declare that over the past 3 years this work has only been funded by NIH (see Acknowledgements).

\section{REFERENCES}

Allain HS, Schuck S, Mauduit N (2000). Depression in Parkinson's disease. BMJ 320: 1287-1288.

Bauer ME, Tejani-Butt SM (1992). Effects of repeated administration of desipramine or electroconvulsive shock on norepinephrine uptake sites measured by $\left[{ }^{3} \mathrm{H}\right]$ nisoxetine autoradiography. Brain Res 582: 208-214.

Benmansour S, Altamirano AV, Jones DJ, Sanchez TA, Gould GG, Pardon MC et al. (2004). Regulation of the norepinephrine transporter by chronic administration of antidepressants. Biol Psychiatry 55: 313-316.
Bonini NM, Giasson BI (2005). Snaring the function of alphasynuclein. Cell 123: 359-361.

Brenz Verca MS, Bahi A, Boyer F, Wagner GC, Dreyer JL (2003). Distribution of alpha- and gamma-synucleins in the adult rat brain and their modification by high-dose cocaine treatment. Eur J Neurosci 18: 1923-1938.

Chandra S, Gallardo G, Fernandez-Chacon R, Schluter OM, Sudhof TC (2005). Alpha-synuclein cooperates with CSPalpha in preventing neurodegeneration. Cell 123: 383-396.

Clayton DF, George JM (1998). The synucleins: a family of proteins involved in synaptic function, plasticity, neurodegeneration and disease. Trends Neurosci 21: 249-254.

Clayton DF, George JM (1999). Synucleins in synaptic plasticity and neurodegenerative disorders. J Neurosci Res 58: 120-129.

Davidson WS, Jonas A, Clayton DV, George JM (1998). Stabilization of alpha-synuclein secondary structure upon binding to synthetic membranes. J Biol Chem 273: 9443-9449.

Detke MJ, Rickels M, Lucki I (1995). Active behaviors in the rat forced swimming test differentially produced by serotonergic and noradrenergic antidepressants. Psychopharmacology (Berl) 121: 66-72.

Donati RJ, Rasenick MM (2005). Chronic antidepressant treatment prevents accumulation of gsalpha in cholesterol-rich, cytoskeletal-associated, plasma membrane domains (lipid rafts). Neuropsychopharmacology 30: 1238-1245.

Fan Y, Limprasert P, Murray IV, Smith AC, Lee VM, Trojanowski JQ et al. (2006). Beta-synuclein modulates alpha-synuclein neurotoxicity by reducing alpha-synuclein protein expression. Hum Mol Genet 15: 3002-3011.

Fisar Z, Anders M, Tvrzicka E, Stankova B (2005). Effect of longterm administration of antidepressants on the lipid composition of brain plasma membranes. Gen Physiol Biophys 24: 221-236.

Fortin DL, Troyer MD, Nakamura K, Kubo S, Anthony MD, Edwards RH (2004). Lipid rafts mediate the synaptic localization of alpha-synuclein. J Neurosci 24: 6715-6723.

Frazer A (1997). Pharmacology of antidepressants. J Clin Psychopharmacol 17(Suppl 1): 2S-18S.

Goedert M (2001). Alpha-synuclein and neurodegenerative diseases. Nat Rev Neurosci 2: 492-501.

Gupta A, Godwin AK, Vanderveer L, Lu A, Liu J (2003a). Hypomethylation of the synuclein gamma gene CpG island promotes its aberrant expression in breast carcinoma and ovarian carcinoma. Cancer Res 63: 664-673.

Gupta A, Inaba S, Wong OK, Fang G, Liu J (2003b). Breast cancerspecific gene 1 interacts with the mitotic checkpoint kinase BubR1. Oncogene 22: 7593-7599.

Hashimoto M, Rockenstein E, Mante M, Mallory M, Masliah E (2001). Beta-Synuclein inhibits alpha-synuclein aggregation: a possible role as an anti-parkinsonian factor. Neuron 32: 213-223.

Hebert C, Habimana A, Elie R, Reader TA (2001). Effects of chronic antidepressant treatments on 5-HT and NA transporters in rat brain: an autoradiographic study. Neurochem Int 38: 63-74.

Inaba S, Li C, Shi YE, Song DQ, Jiang JD, Liu J (2005). Synuclein gamma inhibits the mitotic checkpoint function and promotes chromosomal instability of breast cancer cells. Breast Cancer Res Treat 94: 25-35.

Jayanthi LD, Samuvel DJ, Ramamoorthy S (2004). Regulated internalization and phosphorylation of the native norepinephrine transporter in response to phorbol esters. Evidence for localization in lipid rafts and lipid raft-mediated internalization. J Biol Chem 279: 19315-19326.

Jeannotte AM, Sidhu A (2007). Regulation of the norepinephrine transporter by alpha-synuclein-mediated interactions with microtubules. Eur J Neurosci 26: 1509-1520.

Jensen PH, Nielsen MS, Jakes R, Dotti CG, Goedert M (1998). Binding of alpha-synuclein to brain vesicles is abolished 
by familial Parkinson's disease mutation. J Biol Chem 273: 26292-26294.

Ji H, Liu YE, Jia T, Wang M, Liu J, Xiao G et al. (1997). Identification of a breast cancer-specific gene, BCSG1, by direct differential cDNA sequencing. Cancer Res 57: 759-764.

Klimek V, Stockmeier C, Overholser J, Meltzer HY, Kalka S, Dilley G et al. (1997). Reduced levels of norepinephrine transporters in the locus coeruleus in major depression. J Neurosci 17: 8451-8458.

Kubo S, Nemani VM, Chalkley RJ, Anthony MD, Hattori N, Mizuno Y et al. (2005). A combinatorial code for the interaction of alpha-synuclein with membranes. J Biol Chem 280: 31664-31672.

Lee CM, Javitch JA, Snyder SH (1983). Recognition sites for norepinephrine uptake: regulation by neurotransmitter. Science 220: 626-629.

Lee D, Paik SR, Choi KY (2004). Beta-synuclein exhibits chaperone activity more efficiently than alpha-synuclein. FEBS Lett 576: 256-260.

Lee VM, Trojanowski JQ (2006). Mechanisms of Parkinson's disease linked to pathological alpha-synuclein: new targets for drug discovery. Neuron 52: 33-38.

Liu YE, Pu W, Jiang Y, Shi D, Dackour R, Shi YE (2007). Chaperoning of estrogen receptor and induction of mammary gland proliferation by neuronal protein synuclein gamma. Oncogene 26: 2115-2125.

Melikian HE, McDonald JK, Gu H, Rudnick G, Moore KR, Blakely RD (1994). Human norepinephrine transporter. Biosynthetic studies using a site-directed polyclonal antibody. J Biol Chem 269: 12290-12297.

Miyamoto S, Asakura M, Sasuga Y, Osada K, Bodaiji N, Imafuku J et al. (1997). Effects of long-term treatment with desipramine on microtubule proteins in rat cerebral cortex. Eur J Pharmacol 333: 279-287.

Moussa CE, Wersinger C, Rusnak M, Tomita Y, Sidhu A (2004). Abnormal migration of human wild-type alpha-synuclein upon gel electrophoresis. Neurosci Lett 371: 239-243.

Ostrerova N, Petrucelli L, Farrer M, Mehta N, Choi P, Hardy J et al. (1999). alpha-Synuclein shares physical and functional homology with 14-3-3 proteins. J Neurosci 19: 5782-5791.

Pan ZZ, Bruening W, Giasson BI, Lee VM, Godwin AK (2002). Gamma-synuclein promotes cancer cell survival and inhibits stress- and chemotherapy drug-induced apoptosis by modulating MAPK pathways. J Biol Chem 277: 35050-35060.

Porsolt RD, Anton G, Blavet N, Jalfre M (1978). Behavioural despair in rats: a new model sensitive to antidepressant treatments. Eur J Pharmacol 47: 379-391.
Santos JS, Lee DK, Ramamoorthy A (2004). Effects of antidepressants on the conformation of phospholipid headgroups studied by solid-state NMR. Magn Reson Chem 42: 105-114.

Sidhu A, Wersinger C, Moussa CE, Vernier P (2004). The role of alpha-synuclein in both neuroprotection and neurodegeneration. Ann N Y Acad Sci 1035: 250-270.

Surguchov A, Palazzo RE, Surgucheva I (2001). Gamma synuclein: subcellular localization in neuronal and non-neuronal cells and effect on signal transduction. Cell Motil Cytoskeleton 49: 218-228.

Surguchov A, Surgucheva I, Solessio E, Baehr W (1999). Synoretin-a new protein belonging to the synuclein family. Mol Cell Neurosci 13: 95-103.

Taylor AE, Saint-Cyr JA, Lang AE, Kenny FT (1986). Parkinson's disease and depression. A critical re-evaluation. Brain 109: 279-292.

Tejani-Butt S, Kluczynski J, Pare WP (2003). Strain-dependent modification of behavior following antidepressant treatment. Prog Neuropsychopharmacol Biol Psychiatry 27: 7-14.

Uversky VN, Li J, Souillac P, Millett IS, Doniach S, Jakes R et al. (2002). Biophysical properties of the synucleins and their propensities to fibrillate: inhibition of alpha-synuclein assembly by beta- and gamma-synucleins. J Biol Chem 277: 11970-11978.

Wersinger C, Jeannotte A, Sidhu A (2006a). Attenuation of the norepinephrine transporter activity and trafficking via interactions with alpha-synuclein. Eur J Neurosci 24: 3141-3152.

Wersinger C, Rusnak M, Sidhu A (2006b). Modulation of the trafficking of the human serotonin transporter by human alphasynuclein. Eur J Neurosci 24: 55-64.

Wersinger C, Sidhu A (2005). Disruption of the interaction of alpha-synuclein with microtubules enhances cell surface recruitment of the dopamine transporter. Biochemistry 44: 13612-13624.

Wu K, Weng Z, Tao Q, Lin G, Wu X, Qian H et al. (2003). Stage-specific expression of breast cancer-specific gene gamma-synuclein. Cancer Epidemiol Biomarkers Prev 12: 920-925.

Yavich L, Jäkälä P, Tanila H (2006). Abnormal compartmentalization of norepinephrine in mouse dentate gyrus in alphasynuclein knockout and A30P transgenic mice. I Neurochem 99: 724-732.

Zhu MY, Kim CH, Hwang DY, Baldessarini RJ, Kim KS (2002). Effects of desipramine treatment on norepinephrine transporter gene expression in the cultured SK-N-BE(2)M17 cells and rat brain tissue. J Neurochem 82: 146-153.

Supplementary Information accompanies the paper on the Neuropsychopharmacology website (http://www.nature.com/npp) 